\title{
El sorteo como herramienta de innovación democrática: el potencial de los minipúblicos deliberativos
}

\author{
Sortition as a tool for democratic innovation: \\ The potential of deliberative mini-publics
}

\author{
GABRIEL CAMARELLES \\ Universidad Jaume I de Castellón
}

\section{Cómo citar/Citation}

Camarelles, G. (2021). El sorteo como herramienta de innovación democrática: el potencial de los minipúblicos deliberativos. Revista Española de Ciencia Política, 56, 145-169. Doi: https://doi.org/10.21308/recp.56.06

\section{Resumen}

El sorteo, históricamente empleado en la Grecia clásica, parece estar ante un proceso de resurgimiento, en un intento de paliar la desafección ciudadana y mejorar el funcionamiento de los sistemas representativos. El objetivo principal del presente artículo radica precisamente en reflexionar sobre el uso del sorteo y el potencial de los minipúblicos deliberativos, y analizar si tienen o no la capacidad de aumentar el grado de confianza de la ciudadanía en sus representantes e instituciones. Se concluye que existen ciertas condiciones, que pasan por la implementación de minipúblicos deliberativos aleatorios, bajo las cuales el sorteo podría combinarse con las elecciones para intentar paliar la desafección ciudadana y mejorar el funcionamiento de los sistemas representativos.

Palabras clave: sorteo, minipúblicos deliberativos, desafección ciudadana, igualdad política.

\begin{abstract}
The sortition, historically used in classical Greece, seems to be facing a process of resurgence, in an attempt to alleviate citizen disaffection and to improve the functioning of representative systems. The main objective of this article is, precisely, to reflect on the use of the sortition and the potential of deliberative mini-publics, and to analyze whether or not they have the capacity to increase the degree of citizens' in their representatives and institutions. It is concluded that there are certain conditions, which go through the implementation of random deliberative mini-publics, under which sortition could be combined with elections to try to alleviate citizen disaffection and to improve the functioning of representative systems.
\end{abstract}

Keywords: sortition, deliberative mini-publics, citizen disaffection, political equality. 


\section{INTRODUCCIÓN}

En las últimas décadas, teóricos y filósofos contemporáneos partidarios del sorteo buscan la inspiración, en su gran mayoría, en las formas en que este sistema fue debatido e incorporado ya en la democracia clásica ateniense. Algunos teóricos consideran que solo mirando al pasado y a los primeros usos del sorteo en procesos políticos pueden entenderse los beneficios que este recurso podría ofrecer a las democracias representativas electorales contemporáneas (Bouricious, 2013; Sintomer, 2017; Van Reybrouck, 2017). Una parte considerable de la literatura académica ha desarrollado una gran variedad de propuestas en las que el uso del sorteo podría beneficiar la participación de la ciudadanía, la toma de decisiones políticas y la propia representación política (Carson y Martin, 1999; Sutherland, 2008; Delannoi y Dowlen, 2013). No obstante, muchas de estas propuestas son heterogéneas y no coinciden en la forma en la que el sorteo debería aplicarse. Por ejemplo, algunos autores cambiarían radicalmente la democracia representativa electoral por otra basada en el sorteo (Burnheim, 1985; Guerrero, 2014). No obstante, la tónica general sostiene que el sorteo de por sí no es la fórmula universal para remediar todos los problemas que presenta la democracia representativa; por este motivo, otros autores proponen la práctica del sorteo como un complemento al sistema electoral (Callenbach y Phillips, 1985; Buchstein, 2015; Van Reybrouck, 2017). Es en esta última propuesta, la complementariedad entre las elecciones y el sorteo, donde se apoya el argumentario de la presente investigación.

Hoy en día, el uso del sorteo en política ha evolucionado del campo teórico al práctico, surgiendo numerosas experiencias democráticas a partir de minipúblicos deliberativos durante las últimas décadas. El minipúblico deliberativo consiste en usar el sorteo para seleccionar un microcosmos de la población, un grupo reducido de personas estadísticamente representativo (mismas características y la misma diversidad de la ciudadanía). El minipúblico deliberaría cara a cara sobre temas de interés general, con la aspiración de lograr una opinión contrafactual que podría ser similar a la de la opinión pública, si esta estuviera mejor informada y asesorada dentro de un entorno propicio (Sintomer, 2017). Estas iniciativas ciudadanas aparecieron unas tras otras, y cada nueva de ellas evolucionó sin dejar de mirar hacia atrás, buscando el aprendizaje de experiencias anteriores con la mirada puesta en solucionar los errores previos (Gargarella, 2019). Entre finales del siglo xx y principios del siglo XXI se han ido desarrollando procesos políticos aleatorios en diferentes países occidentales: Australia, Canadá, Irlanda e Islandia, entre otros, han confiado a la ciudadanía la responsabilidad de participar en proyectos políticos que han llegado, incluso, a consolidarse en cambios constitucionales (Lang, 2007; Landemore, 2017; Farrell et al., 2020).

El motivo que explica el renovado interés por los minipúblicos deliberativos aleatorios se vincula al creciente distanciamiento de la ciudadanía de la clase política y las instituciones (Tormey, 2015). Entre los factores que explican este distanciamiento se encuentran la desconfianza, la desafección y la indignación de una parte considerable de la ciudadanía, que guarda serias dudas sobre la capacidad real de la democracia representativa electoral como mecanismo propicio para la resolución de una serie de 
problemas colectivos (Castells, 2012). En respuesta a esta disminución real o percibida de la legitimidad del sistema representativo, algunos Gobiernos han encontrado en los minipúblicos deliberativos innovadoras formas de participación directa de la ciudadanía en la toma de decisiones políticas (Cain et al., 2003; Torfing y Triantafillou, 2011). Existe una amplia variedad de minipúblicos deliberativos: asambleas ciudadanas, conferencias de consenso, células de participación, jurados ciudadanos, etc. (Ryan y Smith, 2014; Lafont, 2017). Pero lo que estos minipúblicos tienen en común es que la selección de sus miembros se realiza por sorteo y que cada ciudadano tiene la misma oportunidad de ser seleccionado. Además, la deliberación es el motor del proceso decisorio, donde se prioriza el poder de las ideas y los mejores argumentos (Michels y Binnema, 2018).

Este artículo describirá brevemente, en primer lugar, la importancia de la selección por sorteo en Atenas, destacando los principales mecanismos para superar sus debilidades. Además, se propone el minipúblico deliberativo como un instrumento que guarda ciertas similitudes con la democracia directa ateniense, y que podría facilitar la complementariedad entre las elecciones y el sorteo. A continuación, se estudian algunos de los problemas estructurales de la participación política y se analiza la aplicabilidad del sorteo en la actualidad, ofreciendo una mirada crítica de los minipúblicos deliberativos. Para terminar, se analiza el potencial y los límites del sorteo en las sociedades contemporáneas, centrándose en las asambleas ciudadanas de Islandia e Irlanda. En las conclusiones, se exponen las condiciones bajo las cuales el sorteo podría combinarse con las elecciones, a través de minipúblicos deliberativos, para intentar paliar la desafección ciudadana y aumentar la confianza y la participación de la ciudadanía en la toma de decisiones en la democracia representativa.

\section{EL SORTEO ATENIENSE COMO MECANISMO DE PROFUNDIZACIÓN DEMOCRÁTICA}

La selección por sorteo, más que en otras ciudades griegas, fue un procedimiento habitual en Atenas. El uso de la selección aleatoria se fue desarrollando con la propia democracia y se utilizó masivamente en los siglos v y IV a.C., durante la edad dorada de la democracia ateniense (Hansen, 1999). A principios de la democracia ateniense se establecieron magistraturas sorteables que se complementaban con otras seleccionadas por elección. Es decir, los atenienses practicaban el sorteo de manera normalizada, pero lo combinaban con la elección como mecanismo complementario. En otras palabras, la elección era un recurso complementario al uso predominante del sorteo. Salvando las circunstancias coyunturales propias de cada época histórica, ¿sería posible intentar habilitar el sorteo como mecanismo complementario a las elecciones en nuestras democracias representativas? Para intentar resolver esta cuestión, antes es importante conocer cómo se realizaba la complementariedad elección-sorteo en la sociedad ateniense $\mathrm{y}$, sobre todo, saber qué mecanismos auxiliares empleaban para intentar paliar los posibles inconvenientes que llevaba implícitos esta práctica. 
La democracia ateniense confiaba a ciudadanos seleccionados por sorteo la responsabilidad de ocupar los órganos de gobierno más relevantes, mientras que la selección por elección solo se utilizaba en algunos supuestos excepcionales (Manin, 1998; Sinclair, 1999). En palabras de Aristóteles (1988), «parece ser democrático que los cargos se den por sorteo, y oligárquico que se den por elección» (Pol. L. IV: 1294b4). Sin embargo, defendía «que las magistraturas se designen por sorteo, todas o las que no requieran experiencia y conocimientos técnicos» (ibid:: 1317b5). Si bien el Estagirita entendía que el sorteo era propio de la democracia y la elección de la oligarquía, contemplaba que ambos mecanismos se debían complementar, al menos en aquellos casos en los que se requerían unos conocimientos especiales.

La democracia ateniense otorgaba un valor considerable a las capacidades especiales presentes solo en algunas personas. Los atenienses reservaban la designación por elección para las magistraturas en las cuales la competencia de los candidatos era vital. En este sentido, los cargos electivos eran los más importantes (Manin, 1998). No obstante, si bien el pueblo elegía a estos líderes políticos, a su vez dichos líderes a través de la oratoria debían convencer con sus propuestas, que debían ser aceptadas de nuevo por el pueblo. Es decir, la elección no les garantizaba que sus decisiones políticas se llevaran a cabo, ya que después estas debían ser aprobadas por la mayoría de los asistentes a la asamblea. Aquí encontramos una diferencia crucial con las democracias actuales: la ciudadanía a través del voto elige a sus representantes, y ahí termina prácticamente su poder de decisión (Crouch, 2004).

El uso del sorteo era una práctica habitual en la sociedad ateniense, y uno de los rasgos característicos de la democracia directa. A su vez, los atenienses lo utilizaban junto con la elección, lo que hacía que sus instituciones encajaran particularmente bien (Manin, 1998). La rendición de cuentas era otro mecanismo que se podría entender como una salvaguarda contra aquellas personas que no desempeñaban con ejemplaridad su cargo, bien por falta de preparación, bien por exceso de ella dirigiéndola hacia sus propios intereses y no hacia los de la comunidad. La rendición de cuentas lleva implícitos otros dos mecanismos propios de la democracia ateniense: la asunción de responsabilidades y la revocación de mandato. O, dicho de otro modo, cuando un magistrado era condenado por su mala praxis debía asumir sus responsabilidades políticas, que podían llegar hasta su destitución (ibid.: 35). Tanto el sorteo como la elección, y su posible complementariedad, no deberían de prescindir de algunas de las iniciativas llevadas a cabo por la sociedad ateniense. No obstante, hay que destacar un hecho importante que repercute directamente en la toma de decisiones políticas y que facilita el hermetismo o cualquier tipo de injerencia externa por parte de la ciudadanía: la ideología política. ¿El sorteo sería capaz de reducir el impacto negativo de la ideología política?

No cabe duda de que la ideología está impregnada en la estructura básica de las organizaciones políticas y es la pieza angular para dirigir la toma de decisiones. Un problema social se puede abordar desde diferentes perspectivas, dependiendo de la concepción ideológica de los representantes políticos. En este sentido, la elección es un punto de partida para orientar la dirección política de una sociedad. Sin embargo, hay 
un importante número de cuestiones que preocupan considerablemente a la ciudadanía y cuyo planteamiento resolutorio es tan universal que dirigirlo ideológicamente solo radicaliza más el problema. En este sentido, la selección por sorteo de minipúblicos deliberativos podría minimizar estos problemas en los que el debate ideológico solo los dificulta, aumentando la desafección ciudadana con la clase política. Es particularmente en estos casos donde la complementariedad elección-sorteo puede ayudar a mejorar la práctica política. Es decir, la ciudadanía a través del voto puede elegir a sus representantes y la línea ideológica para la dirección del Gobierno, mientras que los minipúblicos deliberativos aleatorios podrían favorecer la participación y la deliberación activa sobre cuestiones que preocupan y afectan directamente a una parte importante de la ciudadanía. Esta es la clave para llevar a cabo la complementariedad elección-sorteo en la actualidad. La cuestión es si los minipúblicos deliberativos aleatorios podrían superar las deficiencias que encuentran los defensores de la representación electoral en la democracia directa ateniense.

\section{LOS PROBLEMAS ESTRUCTURALES DE LA PARTICIPACIÓN POLÍTICA Y LOS MINIPÚBLICOS DELIBERATIVOS}

La reflexión acerca de cómo mejorar el funcionamiento de las democracias representativas ha sido un tema ampliamente tratado en la historia del pensamiento político (Bachrach, 1967; Pateman, 1970; Fishkin, 1995; Barber, 2004). Según Canales, la calidad democrática se manifiesta como la búsqueda de ese ideal que hay que conseguir, a sabiendas de que en estado puro no se puede encontrar en ningún lugar del mundo. Ante este reto o deseo inalcanzable surge el regeneracionismo como el pensamiento y la praxis, cuya actitud es proactiva y positiva, e intenta mantener lo positivo del pasado y cambiar lo desfasado e innecesario (Canales, 2018: 3). Esta es la clave: mantener las virtualidades que ofrece la democracia representativa y superar sus debilidades. Un reto que superar por las democracias actuales pasa por paliar el creciente distanciamiento de la ciudadanía con los representantes e instituciones políticas. En este sentido, la alta corrupción y el clientelismo no ayudan a reducir dicho distanciamiento, sino que afectan negativamente la legitimación del Estado moderno y de la propia democracia (Villoria e Izquierdo, 2016).

Muchas voces autorizadas coinciden en que la democracia representativa parece atravesar unos tiempos convulsos y complejos o, al menos, esa es la percepción a la que se puede llegar si consideramos factores como la desconfianza de la ciudadanía en sus dirigentes e instituciones políticas y la desafección ciudadana de la esfera pública, visible en la elevada abstención en las elecciones. La pérdida de afiliados en los partidos políticos y otros factores apuntan hacia un déficit democrático (Crouch, 2004; Mair, 2015; Tormey, 2015). En cualquier caso, recientemente, la política y los políticos están considerados por una parte considerable de la ciudadanía como uno de los grandes problemas que presentan las democracias representativas (Rámirez-Nárdiz, 2014: 184). 
En respuesta a esta disminución real o percibida de la legitimidad del sistema político, la sociedad se ha pronunciado mediante la aparición de sucesivos movimientos ciudadanos que demandan a través de movilizaciones en las calles cambios en el sistema democrático. Unos cambios que se caracterizan por una demanda general de regeneración y profundización democrática. Ante esta nueva realidad social, algunas democracias occidentales han debatido, incorporado y utilizado diferentes instrumentos de participación ciudadana: la iniciativa popular, la consulta popular, la audiencia pública, el presupuesto participativo y la revocatoria de mandato, entre otros, aunque en cantidad, frecuencia y resultados diferentes (Eberhardt, 2015: 85).

Sin embargo, aunque estos mecanismos de participación ciudadana implican el reconocimiento de las autoridades políticas de un nuevo camino paralelo de representación de intereses particulares, a los que se les reconoce la capacidad de intervenir en la toma de decisiones, la iniciativa de los mismos recae en el poder político, que se atribuye el control del proceso, la definición de la agenda y las reglas del juego, y condiciona el acceso de los actores sociales en el proceso de debate público (Ruano de la Fuente, 2010: 106). No obstante, en los últimos años, a estas iniciativas que buscan una mayor profundización democrática se está incorporando una alternativa al debate político que es el potencial del sorteo, al menos como complemento a la representación electoral (Callenbach y Phillips, 1985; McCormick, 2001; Sutherland, 2008; Van Reybrouck, 2017). Concretamente, uno de los principales pilares en los que descansa el sorteo es incrementar la participación de la ciudadanía en la toma de decisiones políticas.

La participación de la ciudadanía a través de las elecciones es un agente legitimador de la democracia representativa actual. A este respecto, se debería realizar una breve aclaración. Es decir, «es necesario distinguir, en primer lugar, entre participación política y participación electoral, siendo la segunda solo una forma de expresión de la primera» (Nohlen, 2004: 138). Hay que destacar que la participación en la democracia directa afianzaba el principio legitimador democrático por dos razones: porque otorgaba a la ciudadanía la oportunidad de elegir a cargos públicos, y porque le ofrecía la posibilidad de participar en la gestión del gobierno. En cambio, la democracia representativa adquiere mayor legitimidad cuanto mayor sea la participación a la hora de elegir a través del voto a aquellos representantes que van a dirigir el gobierno, y poco más. Se evidencia entonces que «en las dos formas de democracia la relación participación y elección se invierte. Mientras hoy la elección es la regla y la participación directa la excepción, tiempo atrás la regla era la participación directa en tanto que la elección era la excepción» (Bobbio, 2005: 404).

No cabe duda de que el sistema representativo electoral presenta una situación paradigmática. Por una parte, atribuyen al electorado plena competencia política a la hora de elegir a sus representantes, pero, por otra, se convierten en el mismo momento en incompetentes a la hora de participar en la toma de decisiones políticas. A su vez, se defiende que el tamaño de nuestras sociedades impide que la ciudadanía pueda participar en el proceso político. Entonces, ¿̨por qué la ciudadanía no puede participar 
en la toma de decisiones políticas, por incompetencia o debido al tamaño de nuestras sociedades? Si hubiera un sistema capaz de facilitar la participación política de la ciudadanía, ¿se convertiría la ciudadanía de nuevo en competente como lo es para elegir a sus representantes políticos? Seguramente, responder a estas cuestiones desde una lógica racional nos llevaría a una conclusión que dejaría al descubierto las verdaderas razones por las cuales los que ostentan el poder no quieren que nada cambie. Schumpeter defiende la elección a través del voto como la esencia de la democracia y el método adecuado para que la ciudadanía pueda seleccionar a los mejores candidatos para gobernarla. Como contrapartida, la ciudadanía tiene la opción de potenciar la rotación de los representantes electos a través del voto en futuros comicios (1996: 335-362). Su razonamiento nos lleva a un contrasentido lógico: si el individuo desciende a un nivel mental inferior al penetrar en la política, ¿de dónde adquiere los conocimientos para saber qué representantes son los mejores? Y en tal caso, ¿atendiendo a qué criterios?

En cuanto al argumento de los electoralistas sobre el problema de escala, Sartori afirma que la democracia de los griegos estaba constituida por ciudadanos de una pequeña comunidad, pero que después de la Revolución francesa ese sistema ya no se puede dar (1993: 18-19). Estos argumentos reduccionistas de la democracia son rebatidos por los partidarios de una democracia más inclusiva. Un argumento que defienden algunos filósofos y teóricos políticos partidarios del sorteo se basa en que la competencia o las habilidades políticas son universales, y se pueden adquirir a través de la experiencia o la educación. Por ejemplo, a través de su propuesta de la democracia fuerte, Barber presenta el potencial de la participación ciudadana como autoaprendizaje para la vida política, a la vez que la política se convierte en su propia universidad. La competencia política está, por tanto, al alcance de toda la ciudadanía sin necesidad de intermediarios especializados (2004: 222-223).

Con relación al problema de escala, que argumentan los electoralistas, Fishkin propone la encuesta de opinión deliberativa (DOP en inglés). Su propuesta apuesta por una deliberación profunda entre un grupo seleccionado por sorteo que, básicamente, ya fue practicada por los jurados populares atenienses en una democracia cara a cara. Este autor sostiene que la DOP ofrece las posibilidades de recrear las condiciones necesarias para una sociedad cara a cara, de manera que sirva a la democracia en un contexto de Estado nación a gran escala (1995: 152-155). La representación descriptiva presente en el grupo de participantes facilita la constitución de un microcosmos estadístico y representativo de la sociedad, con lo cual se puede esperar que las decisiones llevadas a cabo sean las que tomaría el conjunto de la sociedad si tuvieran las mismas oportunidades y condiciones de deliberación (ibid:: 155-173).

Más allá de las importantes divergencias entre los partidarios y los detractores del sorteo, se presentan algunas cuestiones centrales: ¿pueden los minipúblicos deliberativos paliar la creciente desafección ciudadana y aumentar la confianza y la participación de la ciudadanía en los procesos políticos de las democracias contemporáneas? ¿Pueden los minipúblicos deliberativos ofrecer las ventajas de la democracia directa ateniense y salvar sus inconvenientes? 


\section{Una mirada critica a los minipúblicos deliberativos}

Desde principios del siglo XXI se han llevado a cabo algunos proyectos políticos en distintos países occidentales, impulsados por la ciudadanía a través de diferentes iniciativas democráticas. El objetivo de estas innovaciones era mejorar el sistema democrático de una forma particular: revitalizando los componentes fundamentales de la democracia deliberativa (Gargarella, 2019: 40). Estas experiencias se inspiraron de una u otra manera en otros procesos del mismo tipo, y surgieron unas tras otras. Cada nueva experiencia avanzó observando procesos anteriores, intentando aprender de ellos y tratando de corregir los errores cometidos previamente (Suteu, 2015: 259-260).

Los antecedentes más relevantes de minipúblicos o asambleas ciudadanas se produjeron en Canadá. El proceso deliberativo más destacado es la iniciativa llevada a cabo en la Columbia Británica. Aunque no se obtuvo un resultado positivo, se convirtió en un modelo que seguir en el panorama internacional (Carolan, 2015: 735). Esta provincia canadiense inició un proceso deliberativo encargando a una asamblea de ciudadanos la reforma electoral. Esta asamblea estaba formada por 160 miembros elegidos por sorteo. En 2005, Columbia Británica estuvo cerca de convertirse en la primera jurisdicción política a nivel mundial en cambiar su sistema electoral a través de minipúblicos deliberativos aleatorios (Lang, 2007: 36-37). Tras la experiencia de la Columbia Británica, en 2006 la provincia canadiense de Ontario también llevó a cabo un proceso similar para reformar la ley electoral, invitando a participar a un grupo aleatorio de ciudadanos bajo el requisito de estar inscritos en el registro electoral. Del conjunto de candidatos que formalizaron su participación se seleccionó por sorteo una muestra representativa de 103 personas. Al final se rechazó la propuesta de la asamblea ciudadana por el 63\% de los votantes (Van Reybrouck, 2017: 135). En Holanda, el Burgerforum Kiesstelsel ofrece otro ejemplo interesante de minipúblicos o asambleas ciudadanas. El Gobierno holandés fue pionero en el mundo en formalizar una asamblea nacional de ciudadanos a gran escala para realizar una reforma electoral. Sin embargo, el Parlamento rechazó la propuesta de la asamblea ciudadana (Jongh, 2013: 13, 196-197).

Aunque estas iniciativas democráticas no tuvieron el éxito esperado, sirvieron como ejemplo para países como Islandia e Irlanda. En el año 2010, el Gobierno de Islandia impulsó un Foro Nacional para la reforma constitucional. Este foro estaba formado por 950 miembros seleccionados por sorteo siguiendo un sistema de cuotas (Landemore, 2017: 169). En el caso de Irlanda, se llevaron a cabo dos procesos deliberativos: la Convención Constitucional (2012-2014) y la Asamblea de Ciudadanos (2016-2018). El Parlamento estableció una Convención ciudadana formada por 66 miembros seleccionados por sortero, 33 políticos y un presidente independiente, que terminó en un referéndum en 2015 para permitir el matrimonio entre personas del mismo sexo (Elkink et al., 2015: 1-4). En 2016, una asamblea de 100 ciudadanos irlandeses elegidos por sorteo realizó una propuesta de reforma de la Constitución sobre el aborto, y que sería aprobada a través de un referéndum en 2018 (Kenny, 2018: 265-269). 


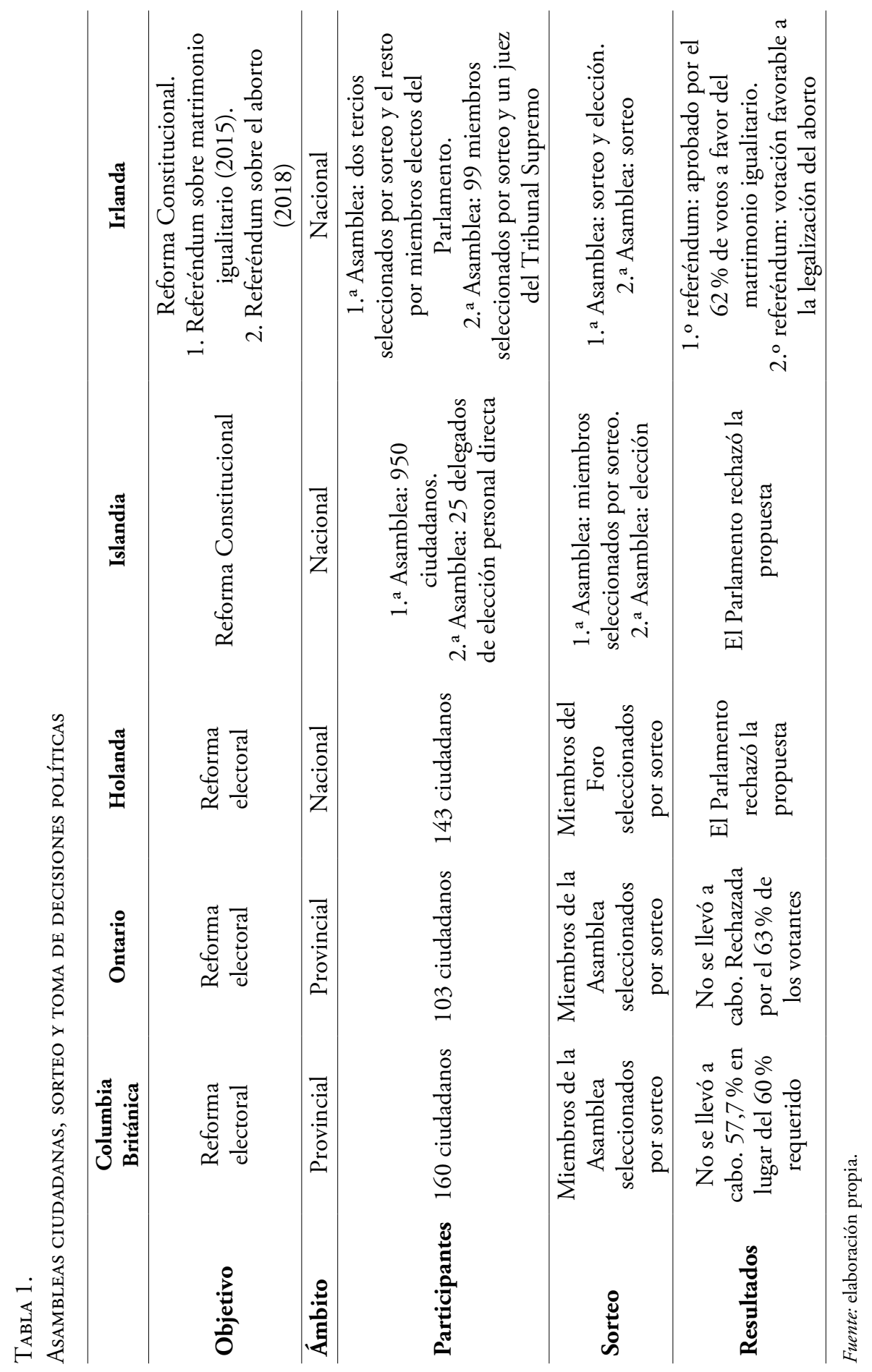


Los minipúblicos deliberativos son un fenómeno reciente en las democracias representativas occidentales (Sintomer, 2017: 33-34). Más allá del éxito real de estas iniciativas asamblearias, se puede considerar que su auténtico valor se encuentra en que han provocado una brecha en el hermético sistema de la representación electoral y, a su vez, una profundización en la legitimidad de la democracia (Gargarella, 2019: 40). Sin embargo, según sus funciones, los minipúblicos deliberativos podrían ocasionar el efecto contrario: disminuir la legitimidad del sistema político (Lafont, 2015). Según Cristina Lafont, el uso de minipúblicos deliberativos en los procesos de toma de decisiones políticas podría disminuir la legitimidad democrática del sistema político (ibid:: 2). ¿Cómo se podría llegar a este punto? La autora sostiene que las funciones de los minipúblicos deliberativos pueden ser diversas, y sobresalen tres formas posibles de implementación: orientación de la opinión pública, informar el debate público y la toma decisiones. Según esta autora, estos últimos pueden ocasionar problemas de legitimidad democrática. Lafont argumenta que cuando los minipúblicos deliberativos toman directamente una decisión, rompen el circuito de retroalimentación con la deliberación real en la esfera pública, disminuyendo la legitimidad democrática del proceso político (ibid:: 3).

Aunque mi crítica comparte parcialmente el argumentario de Lafont, sigo una línea de argumentación diferente al matizar que para potenciar la legitimidad democrática se debe partir de minipúblicos democráticos y decisorios. A su vez, mi argumentario va más allá en cuanto a que la pérdida de legitimidad de los minipúblicos deliberativos está más relacionada con el poder de decisión que les atribuyen los representantes políticos que propiamente en las funciones que desempeñan. Según mi criterio, un minipúblico deliberativo se debería regir por tres principios fundamentales: representación descriptiva o estadística, deliberación cara a cara en grupos reducidos y participación directa de la ciudadanía en la toma de decisiones políticas. ¿Esto significa que un minipúblico deliberativo puede alcanzar plena legitimidad democrática?

Seguramente, no. En este sentido, deberíamos centrar nuestras pretensiones. Por ejemplo, ¿qué estamos pidiendo a los minipúblicos deliberativos, plena legitimidad democrática o potenciarla a razón de aumentar la participación de la ciudadanía en la toma de decisiones y disminuir la creciente distancia entre gobernantes y gobernados? Podríamos considerar que esta es la cuestión clave. En mi opinión, a un minipúblico deliberativo no se le debería pedir plena legitimidad democrática, sino que se le debería exigir que, en la medida de sus posibilidades, vaya incorporando al proceso deliberativo todas aquellas voces que se hayan podido quedar al margen. Esto maximizaría la igualdad política de la ciudadanía y, a su vez, aumentaría la legitimidad democrática del proceso político. En suma, ¿qué virtualidades y limitaciones presentan los minipúblicos deliberativos según los principios expuestos?

La representación descriptiva o estadística parte de una premisa ineludible: la muestra aleatoria tiene que ser un retrato en miniatura de todo el electorado, un microcosmos estadísticamente representativo de la sociedad (Pitkin, 1985: 65-67; Fishkin, 1995: 142). Si esta fuera una metodología ideal, el azar iría reclutando a las personas de manera que el cuerpo representativo se correspondiera con la problemática que tratar. Sin embargo, el azar no tiene estas cualidades; simplemente posibilita tanto que así sea 
como todo lo contrario. Según Lafont, es cuestionable que la selección aleatoria estratificada pueda proporcionar siempre una representación precisa de la población, ya que las categorías sociales difieren según el problema. En este caso, existe el riesgo de que los grupos más implicados en los problemas que tratar no sean capturados debido a las categorías de muestreo utilizadas (Lafont, 2015: 10).

No es fácil cuestionar el argumento que sostiene Lafont. Pero supongamos que desaparece este problema y que todos los implicados están interesados en los problemas específicos. ¿Tendrían entonces juicios homogéneos o la diversidad cognitiva de las personas va más allá de su coincidencia en género, cultura, clase social, profesión, etc.? Debemos considerar que el riesgo cero no existe en ninguna actividad humana. La premisa válida en nuestro caso es que la representación descriptiva puede potenciar la legitimidad democrática al aumentar la participación ciudadana en el proceso político y, con ello, puede aumentar la participación de la ciudadanía y disminuir la distancia con sus representantes políticos.

La fortaleza del minipúblico deliberativo debería radicar en que se incrementa el criterio de imparcialidad o neutralidad. De este modo, la ciudadanía se podría sentir representada, al menos, en su imaginario colectivo. La ciudadanía podría pensar que sus representantes no han sido elegidos conforme a una élite política o por criterios socioeconómicos. Y, sobre todo, el ciudadano común no se sentiría desplazado de la toma de decisiones a favor de unos representantes electos, que la mayoría de los casos no cumplen con sus promesas electorales, sino que se identificaría con unos nuevos representantes con los que comparten intereses y preocupaciones. A su vez, la ciudadanía se sentiría parte del juego político, ya que siempre tendría la posibilidad que ofrece el azar para formar parte de un futuro minipúblico deliberativo.

La deliberación cara a cara es recomendable que sea microcósmica: escoger un grupo, constituido según una muestra aleatoria y relativamente pequeño para que todos tengan igualdad de oportunidades de formar parte con buenas condiciones para deliberar (Fishkin, 2009: 81). Las propuestas de la deliberación microcósmica involucran a ciudadanos y no a expertos o élites políticas, preservando así la igualdad política. No obstante, Lafont sostiene que las opiniones de los ciudadanos comunes se transforman como consecuencia de la experiencia deliberativa. En su opinión, es precisamente la intervención del filtro deliberativo lo que hace que los participantes ya no sean una muestra representativa de la ciudadanía en general porque se han convertido en expertos (Lafont, 2015: 10-11). Ante esta nueva realidad, Lafont duda que en este caso los juicios, digamos de los expertos deliberativos, tengan más fuerza que la de otros expertos con méritos superiores. A su vez, entiende que estos juicios pierden su legitimidad porque ya no son los juicios de la gente.

Desde mi punto de vista, los juicios de los expertos deliberativos poseen más legitimidad que los juicios de los expertos por méritos. Es decir, para llegar a ser experto deliberativo se ha necesitado, entre otros, del asesoramiento de los expertos por méritos. En ese caso, el juicio de un experto deliberativo está formado por un compendio de opiniones de los expertos por méritos consultados. Además, hay que añadir los conocimientos adquiridos en el debate con los demás participantes, ya que durante el proceso van a 
surgir nuevas opiniones que han ido evolucionando con el proceso deliberativo. Y en caso de que el proceso deliberativo convierta a los participantes en una especie de expertos, la legitimidad del proceso no tiene por qué disminuir. Es decir, cualquier persona elegida aleatoriamente no va a poder imponer su voluntad, aunque se convierta en un experto, ya que el proceso deliberativo solo podrá dar validez a la fuerza del mejor argumento.

Como sostiene Habermas (1999), la estructura de la comunicación de los participantes en la argumentación debe excluir toda coacción, ya provenga de fuera de ese proceso de argumentación, ya surja del propio proceso. De este modo se neutraliza cualquier otro motivo que no sea el de la búsqueda cooperativa de la verdad (Habermas, 1999: 46). Sea como fuere, el minipúblico deliberativo no tiene nunca la última palabra porque su toma de decisiones estaría supeditada en última instancia al escrutinio de la ciudadanía.

La participación directa de la ciudadanía en la toma de decisiones políticas es el principio más importante del minipúblico deliberativo para otorgarle una verdadera legitimidad. Cualquier anomalía en los dos primeros principios quedaría en manos de la ciudadanía solucionarla. En este caso, el tercer principio sirve de salvaguarda para que no se lleve a la práctica, ya que la ciudadanía retoma todo el poder decisorio para que la propuesta pueda llevarse a cabo.

Una vez expuestas las funciones más habituales de los minipúblicos deliberativos y los principios fundamentales por los que se deberían regir, se podría argumentar, siguiendo la línea de Lafont, que un minipúblico deliberativo cuya toma de decisiones pase por el filtro de aprobación o denegación de la esfera pública aumenta la legitimidad democrática del proceso decisorio. Tal vez, la misión primaria de todos los minipúblicos deliberativos es alcanzar este objetivo, pero muchos fracasan en el intento. Quizás no por sus deméritos, sino por las circunstancias impuestas desde un poder superior. En todo caso, la crítica de ilegitimidad no se debería dirigir directamente a los minipúblicos, sino a dicho poder que limita sus competencias y los convierten en meros instrumentos ficticios dirigidos a acallar a la ciudadanía, con el objetivo enmascarado de no otorgarles el poder en la toma de decisiones. En pocas palabras, hasta un minipúblico deliberativo modélico podría perder toda su legitimidad si la ratificación de sus decisiones depende en última instancia no de la ciudadanía, sino del Gobierno de turno. En dicho caso, ante el problema que se presenta nos encontramos básicamente con dos tipos de minipúblicos deliberativos: consultivos y decisorios.

La labor de los minipúblicos consultivos es la de deliberar y llegar a un acuerdo sobre un tema en concreto. Llegados a este punto, el Gobierno de turno puede llevar a cabo o no dicha recomendación. En este caso, a mi parecer, la labor del minipúblico deliberativo pierde toda su razón de ser, entendiendo que surgen por un intento de los gobernantes de disminuir el distanciamiento con la ciudadanía, instaurando su uso para tal fin. Si observamos la clásica escalera de la no participación de Arnstein (1969), en general los minipúblicos consultivos se encuentran en los peldaños inferiores:

1) Manipulación. Se reúnen a personas en comités o juntas consultivas con el fin de diseñar su apoyo, distorsionando su participación. 
2) Terapia. Se enmascara la terapia de grupo como participación ciudadana, se involucra a los ciudadanos en la planificación y, en cambio, los expertos los someten a una terapia de grupo clínica con el objetivo de curarlos de su patología, en vez de cambiar los problemas reales.

3) Informar La información es clave para una participación ciudadana legítima; sin embargo, el flujo de la misma es unidireccional (de los funcionarios a los ciudadanos) lo que limita su poder de negociación.

4) Consulta. Consultar a la ciudadanía sin combinarse con otras formas de participación convierte la participación en un mero ritual, ya que no se garantiza que se vayan a tener en cuenta las preocupaciones e ideas de la ciudadanía.

En cambio, para instaurar minipúblicos decisorios, los gobernantes tienen que hacer un gran esfuerzo democrático. Siguiendo con la escalera de Arnstein, el poder ciudadano se encuentra en los peldaños superiores:

7) Poder delegado. Las negociaciones entre funcionarios y ciudadanos son bidireccionales, ya que los ciudadanos pueden llegar a un poder dominante en la toma de decisiones;

8) Control ciudadano. En este nivel, la ciudadanía puede gobernar un programa o una institución, hacerse cargo de los aspectos políticos y ser capaces de negociar en plano de igualdad (Arnstein, 1969).

Evidentemente, llevar a cabo todas las decisiones políticas al terreno de los minipúblicos deliberativos, supondría derrocar el sistema representativo electoral tal y como está constitucionalmente constituido, y perdería su razón de ser. En suma, en mi opinión, los gobernantes deberían llevar a cabo dos importantes reformas políticas: a) implementar una agenda política que cubra las principales preocupaciones e intereses de la ciudadanía, y b) que esta se debata y se implemente con la participación de minipúblicos deliberativos y decisorios, y que las decisiones de estos pasen por el escrutinio de la ciudadanía en un proceso refrendario vinculante.

\section{POSIBILIDADES Y LÍMITES DEL SORTEO EN LAS SOCIEDADES CONTEMPORÁNEAS: LOS CASOS DE ISLANDIA E IRLANDA}

El objetivo de este apartado es presentar algunas de las virtualidades de las asambleas ciudadanas constituyentes en Islandia e Irlanda y, a continuación, reflexionar y analizar algunas cuestiones con el fin de intentar superar algunas de sus limitaciones. La justificación para centrar el análisis en los casos mencionados parte de dos premisas:

- Las asambleas ciudadanas de Islandia e Irlanda sucedieron a las de la Columbia Británica, Ontario y Holanda; sin embargo, su interés radica en que buscaron 
reformas más sustanciales. Estas asambleas fueron más allá de proponer un cambio en el sistema electoral, y trabajaron en una reforma constitucional.

- Aunque los minipúblicos deliberativos o asambleas ciudadanas se han ido implementando en multitud de países (Reino Unido, Francia, Bélgica, España, etc.), Islandia e Irlanda son pioneras en iniciativas asamblearias aleatorias que incluían a la ciudadanía común en cambios constitucionales y son ejemplos innovadores de la utilización de las nuevas tecnologías y las redes sociales en procesos deliberativos.

Para llevar a cabo el presente análisis cualitativo es importante hacerse unas preguntas previas con el fin de establecer unos criterios mínimos para llevarlo a cabo: ¿representan realmente las asambleas ciudadanas aleatorias una amplia gama de los intereses generales de la sociedad? ¿Cómo se lleva a cabo el proceso de participación ciudadana? ¿Los miembros de la asamblea disponen de la información necesaria para formarse un criterio adecuado? ¿Adquiere mayor legitimidad democrática que la toma de decisiones de la asamblea pase por un referéndum en el que participe toda la ciudadanía? ¿El resultado del referéndum popular tiene que ser vinculante o sujeto al criterio del Gobierno central? A partir de estas cuestiones podemos establecer una clasificación conceptual y temporal de la siguiente manera: fase de selección aleatoria; fase de aprendizaje, deliberación y audiencia pública; fase refrendaria y carácter vinculante. Sobre estas fases o criterios se va a estructurar el análisis de las potencialidades y las posibles debilidades de las asambleas ciudadanas constituidas en Islandia e Irlanda.

TABLA 2.

FASES Y COMPARATIVA DE LAS ASAMBLEAS CIUDADANAS DE IRLANDA E IsLANDIA

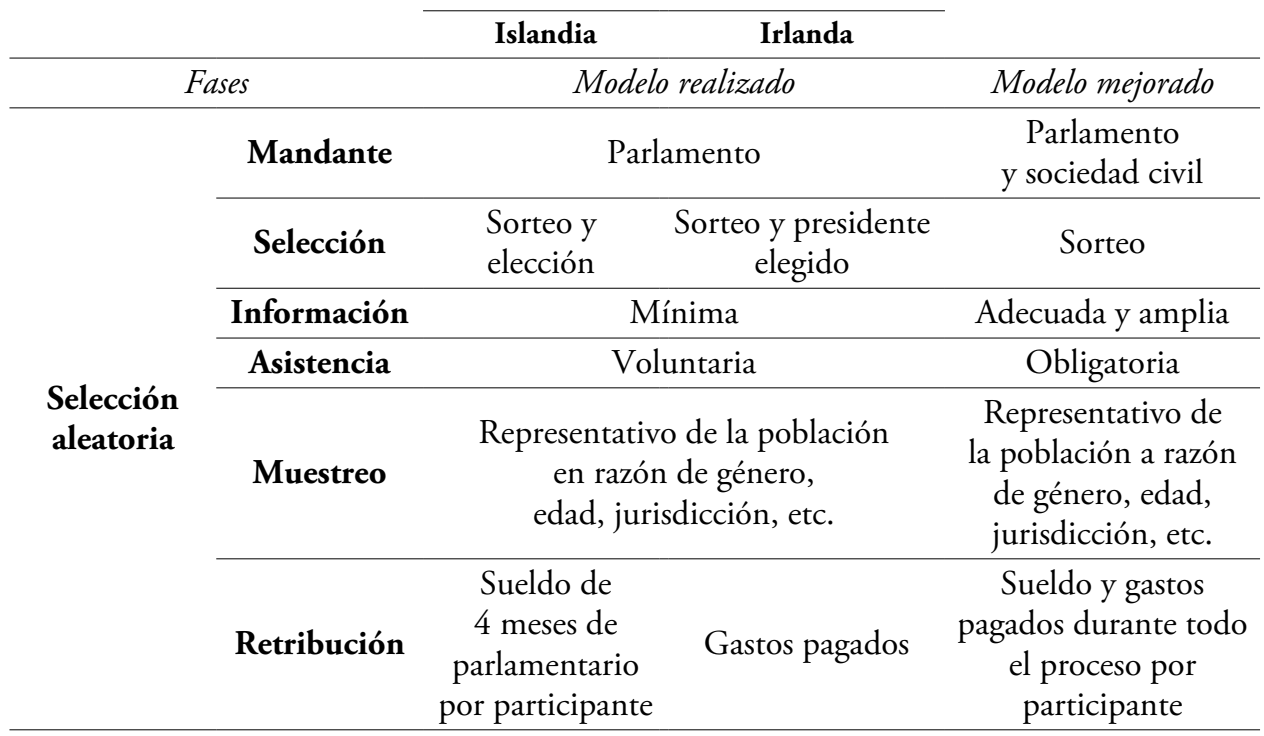




\begin{tabular}{|c|c|c|c|c|}
\hline & \multicolumn{2}{|r|}{ Irlanda } & \multirow[b]{2}{*}{ Modelo mejorado } \\
\hline & uses & Model & o realizado & \\
\hline \multirow{3}{*}{$\begin{array}{c}\text { Aprendizaje, } \\
\text { deliberación } \\
\text { y audiencia } \\
\text { pública }\end{array}$} & Información & Nuevas tecnolo & gías y redes sociales & $\begin{array}{l}\text { Medios tradicionales } \\
\text { de difusión } \\
\text { (televisión, prensa, } \\
\text { radio) y nuevas } \\
\text { tecnologías y redes } \\
\text { sociales }\end{array}$ \\
\hline & Deliberación & $\begin{array}{l}\text { 1. }{ }^{\mathrm{a}} \text { (1 día). } \\
2 .^{\mathrm{a}} \text { (3 meses). } \\
\text { Electorado } \\
\text { registrado con } \\
\text { derecho a enviar } \\
\text { sugerencias a la } \\
\text { asamblea y } \\
\text { debate online. }\end{array}$ & $\begin{array}{l}\text { 1. } .^{\mathrm{a}}(14 \text { meses }) . \\
2 .^{\mathrm{a}} \text { (5 fines de } \\
\text { semana). } \\
\text { 1. } .^{\mathrm{a}} \text { : asesorados } \\
\text { por expertos, } \\
\text { académicos, } \\
\text { asociaciones } \\
\text { civiles, etc. } \\
\text { 2. } .^{\mathrm{a}} \text { : asesorados } \\
\text { por expertos en } \\
\text { medicina, derecho, } \\
\text { ética, etc. }\end{array}$ & $\begin{array}{c}\text { Sin límite de tiempo, } \\
\text { el necesario hasta la } \\
\text { realización de una } \\
\text { propuesta } \\
\text { consensuada. } \\
\text { Asesoramiento } \\
\text { profesional sobre el } \\
\text { tema de debate, lluvia } \\
\text { de ideas de la } \\
\text { ciudadanía en redes } \\
\text { sociales y valoradas } \\
\text { por la asamblea }\end{array}$ \\
\hline & Publicidad & $\begin{array}{l}\text { Plataformas } \\
\text { digitales, actas } \\
\text { públicas en } \\
\text { redes sociales }\end{array}$ & $\begin{array}{c}\text { Presentaciones } \\
\text { de expertos y } \\
\text { propuestas } \\
\text { adelantadas a los } \\
\text { asambleístas por } \\
\text { escrito a través de } \\
\text { medios digitales }\end{array}$ & $\begin{array}{l}\text { Plataformas digitales, } \\
\text { actas públicas en } \\
\text { redes sociales, } \\
\text { participación de la } \\
\text { ciudadanía a través de } \\
\text { medios telemáticos }\end{array}$ \\
\hline $\begin{array}{c}\text { Referéndum } \\
\text { y carácter } \\
\text { vinculante }\end{array}$ & Referéndum & $\begin{array}{c}\text { Consultivo } \\
\text { y no vinculante }\end{array}$ & $\begin{array}{c}\text { Consultivo y } \\
\text { vinculante gracias } \\
\text { a la voluntad } \\
\text { política del } \\
\text { Gobierno }\end{array}$ & $\begin{array}{l}\text { Decisorio y } \\
\text { vinculante }\end{array}$ \\
\hline
\end{tabular}

Fuente: elaboración propia.

\section{Fase de selección aleatoria}

La selección por sorteo potencia la participación y la igualdad de oportunidades de la ciudadanía común en el proceso político y favorece la diversidad cognitiva, aumentando la legitimidad democrática (Landemore, 2013). Cuando se utiliza un amplio número de personas para la selección aleatoria, se posibilita la representación descriptiva de la sociedad: un microcosmos del electorado (Sintomer, 2017: 35; Linares, 2017: 49). Un proceso de selección aleatoria tiene que enviar una circular previa a la 
ciudadanía que explique el motivo por el cual va a entrar en un sorteo de candidatos para formar parte de una asamblea popular y, sobre todo, facilitar la mayor información posible y comprensible de los asuntos que tratar (Dienel y Harms, 2000). Esta información previa ayuda a adquirir unos conocimientos básicos, tanto para aquellas personas que puedan salir sorteadas como para aquellas otras que no lo sean, ya que el capital informativo es clave para la calidad de futuros debates y, sobre todo, para ayudar a la decisión final en el proceso refrendario.

Para que el proceso de selección aleatoria sea lo más representativo posible del electorado, aquel que resulte seleccionado debe saber previamente que no puede renunciar a la candidatura, ya que de hacerlo podría deslegitimar el proceso (Delannoi et al., 2013). Además, ante el riesgo de que puedan quedar fuera algunas voces y perspectivas relevantes a problemas específicos, debido a obligaciones laborales o familiares, la remuneración económica por participar en las asambleas es indispensable. ¿Por qué la voluntariedad puede deslegitimar el proceso deliberativo? ¿Por qué es importante motivar a la ciudadana a participar con incentivos económicos? El principal motivo de no dejar la aceptación al cargo en manos de la voluntariedad, después de ser seleccionado por sorteo, radica en que una representación no descriptiva del electorado llegaría a deslegitimar el proceso político porque, generalmente, están más predispuestas a participar en actos públicos las personas más próximas a organizaciones políticas y, consecuentemente, a tener una opinión ideológicamente formada. Además, ante el riesgo de que las voces y perspectivas relevantes ante problemas específicos puedan quedar fuera, debido a obligaciones laborales o familiares, la remuneración económica puede facilitar que el seleccionado para la asamblea pueda delegar sus obligaciones a otra persona sin repercutir en sus ingresos familiares. Reflexionemos sobre estos criterios.

Por lo general, la voluntariedad reduce la participación pública y, con ello, se pierde uno de los principales beneficios que otorga el sorteo a la política: la representación descriptiva. En cambio, la obligatoriedad suele aumentar la participación pública y, con ello, la decisión final de la asamblea incrementaría su aceptabilidad, ya que todo el electorado estaría inmerso, directa o indirectamente, en el proceso político. Con lo cual, se podría sentir más responsable e identificado con el mismo. Dienel y Harms (2000) sostienen que todo comportamiento humano es el resultado de una determinada motivación. Cuando se desean nuevos comportamientos es necesario proporcionar las motivaciones respectivas (ibid.: 90). Este argumento nos ayuda añadir al carácter sancionador de la obligatoriedad el complemento de incentivos económicos al aceptar ser miembro de la asamblea. La remuneración económica es un factor indispensable para incentivar la participación y que esta sea lo más representativa posible (ibid.: 89).

En cuanto a la remuneración económica por participar, habría que tener en cuenta que fomentar actividades públicas no tiene nada de extraordinario. En la Grecia clásica se asignaba un salario por asistir a las asambleas públicas. Como describe Aristóteles (1988), recibir un salario favorecía que las clases menos privilegiadas y con menos tiempo libre tuvieran más posibilidades de participar en la vida pública (Aristóteles, Pol. 1293a2-7). En la actualidad también se pagan dietas y se facilita la participación 
pública. Un caso bastante conocido se lleva a cabo en el ámbito judicial. Cuando somos seleccionados para formar parte de un jurado popular, en general, la participación es obligatoria y remunerada. No acudir sin causa justificada es motivo de sanción.

Otro caso conocido es la participación en las mesas electorales, que también es obligatoria y remunerada. ¿Qué factores son esenciales para fomentar la participación ciudadana en los jurados populares y las mesas electorales? Creo que la clave está en la obligatoriedad y la remuneración económica. Eso no quiere decir que muchas personas no participarían de manera voluntaria y altruista; pero, por norma general, la participación no sería suficiente para llevar a cabo satisfactoriamente el proceso. Incentivar la máxima participación en los minipúblicos deliberativos es muy importante para fortalecer la legitimidad del proceso y, en muchos casos, es difícil conciliar la participación pública con las obligaciones laborales o familiares. Además, son muchas las personas que desisten en participar en asuntos públicos, simplemente porque no les apetece. Estos son los principales motivos por los que la obligatoriedad y la remuneración económica son criterios imprescindibles para la formación de minipúblicos deliberativos.

A todas estas circunstancias se suman, como afirma Subirats, otras reticencias endémicas o corrientes escépticas a la participación popular que sostienen que: 1) la participación favorece la lentitud del proceso de toma de decisiones: a mayor número de personas a las que consultar, hay que unificar mayor diversidad de criterios, y mayor es la duración y complejidad en el proceso; 2) la partición aumenta los costes del proceso de toma de decisiones: el proceso participativo incrementa los costes de recursos y tiempo, ya que a mayor implicación pública menores son las probabilidades de unificar criterios, esto es, hay mayor número de modificaciones en proyectos que implicarían un aumento de costes; 3) una mayor participación no supone un mayor valor añadido a la decisión; 4) la participación potencia un exceso de particularismos: la defensa de los intereses particulares repercute negativamente en la defensa de los intereses generales; 5) la participación prima el corto plazo: la defensa de los intereses particulares sitúa el debate a corto plazo, ya que los proyectos a medio y largo plazo suelen afectar a algunos intereses inmediatos; 6) la participación debilita instituciones y partidos: los mecanismos representativos provocan una erosión de la legitimidad y la autoridad de instituciones y partidos políticos, ya que proyectan una sombra de desconfianza sobre su capacidad de representación (Subirats, 2001: 37-38).

Tras exponer los argumentos a favor de la obligatoriedad y la remuneración económica, se va a plantear un modelo asambleario mejorado, y con el que se realizará una comparativa con las asambleas deliberativas utilizadas en Islandia e Irlanda. No es la intención minimizar los logros asamblearios conseguidos por estos países, sino más bien intentar mejorar sus procesos deliberativos con la mirada puesta en futuras experiencias asamblearias ciudadanas. ¿Cómo llevó a cabo en Islandia e Irlanda el proceso de selección de candidatos? En el caso de Islandia se constituyó un Foro Nacional con 950 miembros seleccionados estadísticamente y por sorteo (Desai, 2020). El objetivo del foro era informativo, ya que su misión era presentar al Parlamento un informe basado en las demandas ciudadanas (Suteu, 2015). En 2011, el Parlamento islandés 
creó una nueva comisión compuesta por 25 delegados autoseleccionados, donde se excluían a los políticos profesionales (Landemore, 2013).

Con base en un modelo mejorado, la fase de selección aleatoria islandesa muestra algunas deficiencias en términos de igualdad política y, consecuentemente, en legitimidad democrática. El principio de igualdad de oportunidades a la hora de participar, el derecho a una información adecuada al proceso y, sobre todo, el prescindir de los criterios de obligatoriedad y remuneración no se dan en condiciones adecuadas o, simplemente, no se dan. Limitar a 5000 invitaciones la participación influye negativamente en la representatividad descriptiva del electorado, reduciendo la igualdad de oportunidades de la población y, de forma cuantitativa, la diversidad cognitiva. Además, que las invitaciones no se acompañen con información adecuada o de recursos para acceder a la misma, disminuye cualitativamente dicha diversidad cognitiva. El hecho de que solo una parte del electorado sea invitada, prescindiendo del criterio de obligatoriedad, favorece un sesgo de élite, concretamente intelectual, que repercute negativamente en el proceso deliberativo.

Descartar el criterio de remuneración influye en la participación y que esta sea la adecuada para legitimar el proceso. No obstante, el proceso islandés presenta deficiencias de forma, pero no tanto de fondo. Si todos los medios utilizados de forma dispersa se hubieran unificado desde un principio, tal vez el resultado final hubiera sido diferente. En suma, en la parte positiva encontramos que en el proceso islandés se buscó una muestra representativa de la población, se apostó por la información telemática y se excluyó a los políticos profesionales del proceso deliberativo. En la parte negativa, encontramos que se priorizó la voluntariedad a la obligatoriedad, no se estipuló un salario por participar en el proceso deliberativo y hubo excesiva burocracia.

En el caso de Irlanda, la Convención Constitucional de 2012 fue de carácter mixto: dos tercios de sus miembros fueron seleccionados por sorteo y el resto eran miembros del Parlamento. Esta convención estuvo formada por 66 ciudadanos comunes, 33 miembros del Parlamento y un presidente elegido por consenso. Los expertos fueron excluidos. Sin embargo, se aceptó el asesoramiento de politólogos, constitucionalistas y académicos (Farrell et al., 2020). La Asamblea de 2016 siguió los pasos de su antecesora de 2012, si bien estuvo compuesta por 99 ciudadanos seleccionados por sorteo y un presidente elegido. En ambas asambleas una empresa privada se encargó de realizar la selección por sorteo atendiendo a una muestra representativa de acuerdo con variantes demográficas: sexo, edad, clase social y territorio. Irlanda, si bien presenta algunas de las deficiencias de Islandia (voluntariedad y no remuneración), mejoró la representación descriptiva al ampliar la base de muestreo. Con ello, se mejoró considerablemente la igualdad de oportunidades de la ciudadanía, aumentando la legitimidad del proceso deliberativo. Un hecho para tener en cuenta es que, si bien a la ciudadanía no se le entregó instrucciones al uso en sus domicilios, su derecho a la información se vio satisfecho, cuantitativa y cualitativamente, por la masiva campaña que se llevó a cabo desde las instituciones, tanto por medios convencionales como telemáticos. Este aspecto es clave, como se vería en el aumento considerable de participación en su posterior proceso refrendario. 


\section{Fase de aprendizaje, deliberación y audiencia pública}

Aunque la fase de aprendizaje, deliberación y audiencia pública de las asambleas ciudadanas islandesas e irlandesas, si bien no fue ejemplar en sus inicios, fue mejorando a medida que se iba consolidando. El inicio de este proceso estuvo supeditado a una problemática anterior: la falta de información accesible y comprensible. No obstante, el recurso de utilizar las nuevas tecnologías y las redes sociales dio un impulso de calado a los procesos informativo y participativo.

Islandia tuvo que realizar dos asambleas previas antes de constituir la asamblea definitiva. El proceso de las asambleas de 2009 y 2010 se llevó a cabo en un solo día (Gargarella, 2019: 47). En cambio, la asamblea de 2011 se reunió durante tres meses y se podría haber reunido un mes más en el caso de haber sido necesario. El proceso de redacción constitucional y audiencia pública fue extraordinariamente abierto, ya que todo el electorado registrado podía enviar sus sugerencias a la asamblea, y de ser aceptadas se podían debatir online. A este respecto, se diseñaron plataformas digitales y los horarios de las sus reuniones y las actas se hicieron públicas en las redes sociales (ibid.: 48). Islandia se convirtió en todo un referente internacional, concretamente por la utilización de las nuevas tecnologías de internet, en especial de las redes sociales. No obstante, Islandia presenta fuertes debilidades en el inicio de este proceso. Además, el excesivo número de asambleas previas a la definitiva fue negativo para la legitimidad del proceso, más aún si tenemos en cuenta que la asamblea definitiva fue por elección directa y no se constituyó por sorteo. En el haber de la asamblea definitiva hay que destacar que se excluyeron los políticos profesionales. Y, sobre todo, fue modélica en cuanto a la utilización de internet, el diseño de plataformas digitales y la utilización de las redes sociales. Estos factores impulsaron positivamente el proceso de audición pública. Estas aportaciones son importantísimas de cara a un modelo mejorado en vistas a futuros procesos asamblearios.

En los casos de Irlanda, la Convención Constitucional de 2012 y la Asamblea de 2016 fueron sendos éxitos refrendarios, lo que puede llevar a la conclusión de que el proceso de aprendizaje, deliberación y audiencia pública fue modélico. Sin embargo, observamos que el éxito alcanzado pudo venir por factores impredecibles o, en su caso, predecibles, al tratarse de problemas más o menos endémicos que la ciudadanía deseaba solucionar, y la clase política accedió a sus demandas. En cuanto al tiempo de aprendizaje, deliberación y audiencia pública, la Convención de 2012 trabajó durante catorce meses (una vez al mes), y en las deliberaciones participaron expertos, académicos, asociaciones civiles, etc. (Arnold et al., 2018). La Asamblea de 2016 funcionó como un minipúblico deliberativo y escuchó previamente a expertos en medicina, derecho, ética y defensores de ambos lados del debate. Esta asamblea se reunió durante cinco fines de semana: los sábados durante todo el día y los domingos por la mañana. Los miembros de la asamblea estaban distribuidos en mesas redondas de siete u ocho personas. Las mesas de debate estaban coordinadas por un facilitador y un encargado de tomar apuntes (Farrell et al., 2020: 116).

En cuanto al proceso de aprendizaje, deliberación y audiencia pública, Irlanda presenta una presentación modélica: sesiones basadas en presentaciones de expertos 
sobre ideas adelantadas a los asambleístas por escrito, presentaciones de grupos de ciudadanos, ronda de preguntas y respuestas, debates en grupos reducidos y espacios de reflexión en donde se invitaba a cada participante a exponer sus impresiones personales sobre cuestiones diversas. El único inconveniente que se observa es el hecho de que los miembros de la asamblea accedieran de manera voluntaria y, en su caso, que no recibieran una remuneración a pesar de la dura agenda que debían llevar a cabo.

\section{Fase refrendaria y su carácter vinculante}

El Parlamento islandés acordó llevar el proyecto constitucional a un referéndum nacional, que se celebró el 20 de octubre de 2012 y que obtuvo una participación del $50 \%$ del electorado. Sin embargo, el carácter no vinculante del referéndum dejó en manos del Parlamento la ratificación de las propuestas. En este sentido, las elecciones de 2013 dieron como ganadores a los opositores del Gobierno y la propuesta de reforma constitucional quedó sin efecto (Gargarella, 2019: 48-49). En este sentido, se defiende que un referéndum popular no debería ser consultivo, sino decisorio y vinculante. En Irlanda, las propuestas de la Convención de 2012 fueron más consultivas que declarativas (Farrell et al., 2020). Sin embargo, hubo una que adquirió especial relevancia: la celebración de un referéndum sobre el matrimonio igualitario (Elkink $e t$ al., 2015), que fue sometido a un referéndum celebrado el 22 de mayo de 2015, donde fue aprobado con el apoyo del $62 \%$ del electorado. Esta fue la primera consulta popular en la historia irlandesa convocada a través de un proceso de deliberación pública (Ryan, 2015).

Un aspecto importante que potenció la participación popular fue, sin duda, que las cuestiones relacionadas con el proceso refrendario fueron debatidas ampliamente en los medios de comunicación, tanto tradicionales como por internet, a lo largo de la campaña (Elkink et al., 2015). El 25 de mayo de 2018 se celebró un referéndum con el 66,4\% del electorado a favor de derogar el aborto (Donnelly y Murray, 2020). El éxito de las asambleas irlandesas nos lleva a reflexionar sobre si fue mérito de la voluntad popular o por el beneplácito de la clase política. Hay que tener en cuenta que la mayoría de los partidos políticos irlandeses estaban a favor del matrimonio igualitario, si bien en el caso del aborto las fuerzas estaban más igualadas.

Los procesos asamblearios llevados a cabo en Islandia e Irlanda han constituido un importante referente internacional, tanto por conseguir un aperturismo en el hermético sistema institucional, como por demostrar que el sistema electoral puede dejar de ser una estructura rígida e inamovible. En suma, la toma de decisiones de las asambleas ciudadanas llevadas a cabo en estos países no fue vinculante; sin embargo, los casos de Irlanda tuvieron el éxito esperado por la mayoría de la ciudadanía. Si comparáramos el fracaso del proyecto islandés con los proyectos irlandeses, se podría convenir que el primero no tuvo éxito por la falta de apoyo de la clase política, mientras que en los proyectos irlandeses fue la clase política la que respaldo las propuestas ciudadanas. Al menos, no pusieron trabas para que no se llevaran a cabo. 
En conclusión, en un modelo asambleario mejorado se debería apostar por un referéndum decisorio y vinculante, ya que la voz popular no puede quedar en manos de la aceptación o rechazo del Gobierno de turno.

\section{CONCLUSIONES}

La revisión del sorteo practicado en la Grecia clásica nos ha permitido constatar que, pese a ser la cuna de la democracia occidental, muchos de los mecanismos utilizados para paliar las carencias del sistema democrático (profesionalización de la política, monopolización del poder en manos de expertos, incompetencia de la clase política, falta de transparencia pública y escasa asunción de responsabilidades, etc.) no se han tenido en cuenta en las democracias actuales, o simplemente no se han puesto los medios suficientes para llevarse a cabo de manera eficaz. Además, se ha puesto de manifiesto que algunos de los problemas que encuentran los detractores de la democracia directa (incompetencia política y el tamaño de nuestras sociedades) se podrían dejar atrás si se utilizaran minipúblicos deliberativos, ya que se podría favorecer la complementariedad entre la elección y el sorteo.

Al realizar una mirada crítica a los minipúblicos deliberativos, se ha podido comprobar que, pese al auge de estas iniciativas, existen algunas lagunas en su funcionalidad. Por tanto, se han aportado unos criterios mínimos que dichos procesos deberían cumplir para ser considerados democráticos: la representación descriptiva o estadística, la deliberación cara a cara y la participación directa de la ciudadanía. Además, se ha realizado una clasificación de los minipúblicos deliberativos en consultivos y decisorios, apostando por los minipúblicos deliberativos decisorios para que el proceso político adquiera una adecuada legitimidad democrática. Sin embargo, sabiendo del riesgo que supone que estos rompan el circuito de retroalimentación con la deliberación real en la esfera pública al disminuir la legitimidad democrática del proceso político, se defiende que las decisiones de los minipúblicos deliberativos se lleven a un referéndum popular y vinculante, en el cual la decisión final pase por el escrutinio de la ciudadanía.

Para el análisis empírico hemos seleccionado los procesos asamblearios de Islandia e Irlanda, en los que la participación ciudadana fue promovida y regulada institucionalmente desde el Gobierno. Aunque nuestra investigación confirma que los procesos deliberativos implementados en Islandia e Irlanda han mostrado algunas deficiencias importantes con relación a los requisitos mínimos expuestos para poder ser considerados democráticos, al menos han llevado la toma de decisión final a un referéndum popular. Y, sobre todo, han sido todo un ejemplo de participación y transparencia al utilizar las nuevas tecnologías de la información y la comunicación a partir del uso masivo de las redes sociales de internet.

La presentación de un modelo asambleario mejorado invita a futuras iniciativas asamblearias en general a tomar en cuenta los criterios mínimos que un proceso de estas características requiere para evitar que todo el trabajo realizado no quede en manos del 
Gobierno de turno, y que surja la desafección y el desencanto de la ciudadanía, como ocurrió en la experiencia islandesa. Apostar por los minipúblicos deliberativos no significa que con ello se terminen los principales males de la democracia representativa, pero creo que se deberían llevar a cabo iniciativas políticas de este tipo, en las que el pueblo participe realmente, directa o indirectamente, en la toma de decisiones políticas. Claro está, si se desea mejorar la legitimidad del sistema representativo de las democracias actuales.

\section{Referencias}

Aristóteles. 1988. Politica. Madrid: Gredos.

Arnold, Tom, David Farrell y Jane Suiter. 2018. «Lessons from a Hybrid Sortition Chamber: The 2012-14 Iris Constitutional Convention», en John Gastill y Erik Olin Wright (eds.), Legislature by Lot. Transformative Designs for Deliberative Governance. Londres: Verso.

Arnstein, Sherry R. 1969. "A ladder of citizen participation", Journal of the American Institute of Planners, 35 (4): 216-224. Disponible en: https://doi.org/10.1080/ 01944366908977225.

Bachrach, Peter. 1967. Critica de la teoría elitista de la democracia. Buenos Aires: Amorrortu.

Barber, Benjamin. 2004. Democracia fuerte. Córdoba: Editorial Almuzara.

Bobbio, Norberto. 2005. Teoría general de la política. Madrid: Trotta.

Bouricious, Terrill. 2013. «Democracy Through Multi-Body Sortition: Athenian Lessons for the Modern Day», Journal of Public Deliberation, 9 (1): 1-19. Disponible en: https://www.publicdeliberation.net/jpd/vol9/iss1/art11.

Buchstein, Hubertus. 2015. «Elective and Aleatory Parliamentarism», en Kari Palonen y José María Rosales (eds.), Parliamentarism and Democratic Theory. Toronto: Barbara Budrich Publishers. Disponible en: https://doi.org/10.2307/j.ctvddzxp8.16.

Burnheim, John. 1985. Is Democracy Possible? The alternative to electoral politics. California: University of California Press.

Cain, Bruce E., Russell J. Dalton y Susan E. Scarrow. 2003. Democracy Transformed? Expanding Political Opportunities in Advanced Industrial Democracies. Nueva York: Oxford University Press. Disponible en: https://doi.org/10.1093/0199264996.00 1.0001 .

Callenbach, Ernest y Michael Phillips. 1985. A Citizen Legislature. Berkeley: Banyan Tree Books.

Canales, José Manuel. 2018. «Algunas reflexiones sobre la regeneración y la calidad democrática. Especial consideración de la situación española», en José Manuel Canales y Ángel Valencia (eds.), Estrategias para la calidad y la regeneración de la democracia. Granada: Editorial Comares.

Carolan, Eoin. 2015. «Ireland's Constitutional Convention: Behind the hype about citizen-led constitutional change», International Journal Constitutional Law, 13 (3): 733-748. Disponible en: https://doi.org/10.1093/icon/mov044. 
Carson, Lyn y Brian Martin. 1999. Random Selection in Politics. Westport: Praeger Publishers.

Castells, Manuel. 2012. Redes de indignación y esperanza: los movimientos sociales en la era de Internet. Madrid: Alianza Editorial.

Crouch, Colin. 2004. Posdemocracia. Madrid: Taurus.

Delannoi, Gil, Oliver Dowlen y Peter Stone. 2013. The Lottery as a Democratic Institution. Studies in Public Policy, 28. Dublin: The Policy Institute, Trinity College.

Desai, Previn. 2020. Constitutional Conventions and Citizen's Assemblies: power to the people? House of Commons Library. Disponible en: https:/cutt.ly/Xn93d1N.

Dienel, Peter y Hans Harms. 2000. Repensar la democracia. Los núcleos de intervención participativa. Barcelona: Ediciones Serbal.

Donnelly, Mary y Claire Murray. 2020. «Abortion care in Ireland: Developing legal and ethical frameworks for conscientious provision», International Journal of Gynecology Obstetrics, 148 (1): 127-132. Disponible en: https://doi.org/10.1002/ ijgo.13025.

Eberhardt, M. Laura. 2015. «Democracias representativas en crisis. Democracia participativa y mecanismos de participación ciudadana como opción", Araucaria. Revista Iberoamericana de Filosofía, Politica y Humanidades, 33: 83-106. Disponible en: http://dx.doi.org/10.12795/araucaria.2014.i33.04.

Elkink, Johan A., David M. Farrell, Theresa Reidy y Jane Suiter. 2015. «Understanding the 2015 Marriage Referendum in Ireland: Constitutional Convention, Campaign, and Conservative Ireland», Irish Political Studies, 32 (3): 361-381. Disponible en: https://doi.org/10.1080/07907184.2016.1197209.

Farrell, David M., Jane Suiter, Clodagh Harris y Kevin Cunningham. 2020. «The Effects of Mixed Membership in a Deliberative Forum: The Irish Constitutional Convention of 2012-2014», Political Studies, 68 (1): 54-73. Disponible en: https:// doi.org/10.1177/0032321719830936.

Fishkin, James S. 1995. Democracia y deliberación. Barcelona: Ariel.

Fishkin, James S. 2009. When the People Speak, Deliberation Democracy and Public Consultation. Oxford: Oxford University Press.

Gargarella, Roberto. 2019. «De la democracia participativa a la deliberación inclusiva: “minipúblicos”, loterías y Constituciones elaboradas por la ciudadanía (crowdsourced constitutions). Comentarios muy preliminares». Revista del Centro de Estudios Constitucionales, 5 (9): 39-63. Disponible en: https://cutt.ly/Jn93WkE.

Guerrero, Alexander A. 2014. "The Lottocratic Alternative», Philosophy and Public Affairs, 42: 135-178. Disponible en: https://doi.org/10.1111/papa.12029.

Habermas, Jürgen. 1999. Teoría de la acción comunicativa, I. Racionalidad de la acción y racionalidad social. Madrid: Grupo Santillana de Ediciones.

Hansen, Mogens H. 1999. The Athenian Democracy in the Age of Demosthenes. Structure, Principles, and Ideology. Norman: University of Oklahoma Press.

Jongh, Matthijs de. 2013. Group dynamics in the Citizens'Assembly on Electoral Reform. Utrecht: Utrecht University. 
Kenny, David. 2018. "Abortion, the Irish Constitution, and constitutional change», Revista de Investigaçóes Constitucionais, 5 (3): 257-275. Disponible en: http:// dx.doi.org/10.5380/rinc.v5i3.60967.

Lafont, Cristina. 2015. «Deliberation, Participation, and Democratic Legitimacy: Should Deliberative Mini-publics Shape Public Policy?», The Journal of Political Philosophy, 23 (1): 40-63. Disponible en: https://doi.org/10.1111/jopp.12031.

Landemore, Hélène. 2013. "Deliberation, cognitive diversity, and democratic inclusiveness: an epistemic argument for the random selection of representatives», Synthese, 190: 1209-1231. Disponible en: https://doi.org/10.1007/s11229-012-0062-6.

Lang, Amy. 2007. «But Is It for Real? The British Columbia Citizens" Assembly as a Model of State-Sponsored Citizen Empowerment», Politics and Society, 1: 35-70. Disponible en: https://doi.org/10.1177/0032329206297147.

Linares, Sebastián. 2017. «Democracia y sorteo de cargos», Daimon. Revista Internacional de Filosofía, 72: 45-58. Disponible en: http://dx.doi.org/10.6018/daimon/294741.

Manin, Bernard. 1998. Los principios del gobierno representativo. Madrid: Alianza Editorial.

McCormick, John P. 2011. Machiavellian Democracy. Cambridge: Cambridge University Press.

Michels, Ank y Harmen Binnema. 2018. «Deepening and Connecting Democratic Processes. The Opportunities and Pitfalls of Mini-Publics in Renewing Democracy", SocialSciences, 7, 236. Disponibleen: https://doi.org/10.3390/socsci7110236.

Nohlen, Dieter. 2004. "La participación electoral como objeto de estudio». Elecciones, 3: $137-157$.

Pateman, Carole. 1970. Participation and Democratic Theory. Cambridge: Cambridge University Press. Disponible en: https://doi.org/10.1017/CBO9780511720444.

Pitkin, Hanna. 1985. El concepto de representación. Madrid: Centro de Estudios Políticos y Constitucionales.

Ramírez-Nárdiz, Alfredo. 2014. «La participación como respuesta a la crisis de la representación: el rol de la democracia participativa», Revista de Derecho Politico, 90: 177-210. Disponible en: https://doi.org/10.5944/rdp.90.2014.13160.

Ruano de la Fuente, José Manuel. 2010. «Contra la participación: discurso y realidad de las experiencias de participación ciudadana», Política y Sociedad, 47 (3): 93-108.

Ryan, Fergus. 2015. «Ireland's Marriage Referendum: A Constitutional Perspective». DPCE online, 2. Disponible en: https://cutt.ly/dn93BHL.

Ryan, Matthew y Graham Smith. 2014. "Defining mini-publics», en Kimmo Grönlund, André Bächtiger y Maija Setälä (eds.), Deliberation Mini-publics. Involving Citizens in the democratic Process. Colchester: ECPR Press.

Sartori, Giovanni. 1993. ¿Qué es la democracia? México: Editorial Patria.

Schumpeter, Joseph A. 1996. Capitalismo, socialismo y democracia (vol. 2). Barcelona: Folio.

Sintomer, Yves. 2017. «Sorteo y política: ¿de la democracia radical a la democracia deliberativa?», Daimon Revista Internacional de Filosofía, 72: 25-43. Disponible en: https://doi.org/10.6018/daimon/295531. 
Subirats, Joan. 2001. «Nuevos mecanismos participativos y democracia: promesas y amenazas», en Joan Font (ed.), Ciudadanos y decisiones públicas. Barcelona: Ariel.

Suteu, Silvia. 2015. "Constitutional Conventions in the Digital Era: Lessons from Iceland and Ireland», Boston College International and Comparative Law Review, 38: 251-276. Disponible en: https://cutt.ly/ln933LE.

Sutherland, Keith. 2008. People's Parliament. Exeter: Academic.

Torfing, Jacob y Peter Triantafillou. 2011. Interactive Policy Marking, Metagovernance and Democracy. Colchester: ECPR Press.

Tormey, Simon. 2015. «Democracy will never be the same again: 21st Century Protest and the Transformation of Politics». Recerca. Revista de Pensament i análisis, 17: 107-128. Disponible en: http://dx.doi.org/10.6035/Recerca.2015.17.6.

Van Reybrouck, David. 2017. Contra las elecciones: cómo salvar la democracia. Barcelona: Grupo Editorial.

Villoria-Mendieta, Manuel y Agustín Izquierdo-Sánchez. 2016. Ética pública y buen gobierno: regenerando la democracia y luchando contra la corrupción desde el servicio público. Madrid: Editorial Tecnos.

Presentado para evaluación: 20 de diciembre de 2020.

Aceptado para publicación: 7 de junio de 2021.

\section{GABRIEL CAMARELLES}

gabycamarelles@hotmail.com

Investigador predoctoral en Ética y Democracia en la Universidad Jaume I de Castellón. Es graduado en Humanidades: Estudios Interculturales, y en Historia y Patrimonio por la Universidad Jaume I de Castellón. Máster universitario en Ética y Democracia por la Universidad de Valencia y la Universidad Jaume I de Castellón. Sus trabajos como investigador se han centrado fundamentalmente en el sorteo como un mecanismo de profundización democrática, los minipúblicos deliberativos aleatorios y las asambleas ciudadanas. Sus publicaciones más recientes son: "Contra las elecciones. Cómo salvar la democracia», reseña de Van Reybrouck (Recerca, 24, 1); "Crítica al fundamentalismo electoral a través del mecanismo del sorteo: propuestas democráticas de Burnheim y Goodwin desde una perspectiva crítica» (Foro Interno. Anuario de Teoría Politica, 21), y "Asambleas ciudadanas y reformas constitucionales en Islandia e Irlanda: sorteo y deliberación como instrumentos de profundización democrática» (Daimon. Revista Internacional de Filosofía). 